\title{
Familial Arteriopathy with Associated Pulmonary and Systemic Arterial Stenoses
}

\author{
A. H. MCDONALD, L. M. GERLIS, AND JANE SOMERVILLE \\ From the National Heart Hospital and Institute of Cardiology, London W.1, and the Department of Pathology, \\ Grimsby General Hospital, Grimsby, Lincolnshire
}

Pulmonary artery stenosis may be single or multiple. Chevers (1846) and Schwalbe (1909) described the condition at necropsy, but it is only in recent years that these stenoses have been diagnosed during life. Arvidsson and his colleagues (1961) noted multiple pulmonary artery stenoses after maternal rubella, and this association was established by Rowe (1963) and confirmed by Emmanouilides, Linde, and Crittenden (1964). Multiple pulmonary artery stenoses have also been found with a syndrome characterized by mental retardation, curious facies, and supravalvar aortic stenosis (William, Barratt-Boyes, and Lowe, 1961; Beuren et al., 1964). Diffuse arterial narrowing has been described in patients with normal faces and normal mental function (Watson, 1963; Bourassa and Campeau, 1963; Mudd, Walter, and Willman, 1965), and the familial occurrence of pulmonary arterial stenoses has been documented by others (Arvidsson, Karnell, and Möller, 1955; Van Epps, 1957; McCue et al., 1965). This paper reports a family with mother and three children affected by a diffuse unusual arteriopathy which was associated with multiple peripheral pulmonary artery stenoses and supravalvar aortic stenosis.

\section{CAse Reports \\ Case 1}

A woman aged 25 years. A heart murmur was noted at 11 years, but she was asymptomatic and had had 4 full-term pregnancies without symptoms.

Examination showed a normal face and physique (Fig. 1). The arterial pulses were normal, and the blood pressure was $120 / 90 \mathrm{~mm}$. $\mathrm{Hg}$ in both arms. The jugular venous pulse was normal. Auscultation showed normal heart sounds with physiological splitting of the second sound; a continuous murmur, loudest on inspiration, was heard over the praecordium and posteriorly over both lungs. No bruits were heard at other sites.

Received December 13, 1968.

\section{Investigations}

Blood. Hb, 11.7 g. $/ 100 \mathrm{ml}$; ESR, $3 \mathrm{~mm} . / \mathrm{hr}$; blood group, A Rh positive; serum calcium, $9.4 \mathrm{mg}$. $100 \mathrm{ml}$.; serum phosphorus, $4 \cdot 2 \mathrm{mg}$./100 ml.; alkaline phosphatase, 9 King-Armstrong units; karyotype, normal female.

Urinary excretion of mucopolysaccharides and hydroxyproline, normal. Chest radiograph showed a normal-sized heart, with dilatation of the main pulmonary artery, and oligaemic lung fields (Fig. 2). Electrocardiogram showed a normal frontal axis, sinus rhythm with dominant $R$ wave in leads V1 and V2 indicating mild right ventricular hypertrophy. At cardiac catheterization (Table), the main pulmonary artery pressure was raised. There was no gradient between the aorta and left ventricle or evidence of intracardiac shunts. Right ventricular angiocardiography showed multiple peripheral pulmonary artery stenoses (Fig. 3a), and an aortogram showed slight supravalvar aortic narrowing (Fig. 3b).

\section{Case 2}

A girl aged 4 years was the product of the second pregnancy of Case 1. The birthweight was $3175 \mathrm{~g}$., and there had been no maternal illness during pregnancy. At the age of 6 weeks the child was admitted to hospital with bronchopneumonia, and was found to have cardiac failure which responded to digitalization. A clinical diagnosis of pulmonary valve stenosis was made. Subsequently central cyanosis was noted after effort, and at 6 months there was a recurrence of bronchopneumonia with cardiac failure which responded to conventional therapy. Thereafter the child was well though limited in her effort tolerance by dyspnoea.

Examination revealed an alert active child with normal face (Fig. 1). There was slight clubbing of the fingers, and central cyanosis was noted after effort. The pulses were normal, and the blood pressure was $110 / 70 \mathrm{~mm}$. $\mathrm{Hg}$ and equal in both arms. The jugular venous pressure was slightly raised, with a dominant " $a$ " wave, and there was a powerful right ventricular lift in the parasternal area. Auscultation demonstrated loud pulmonary valve 


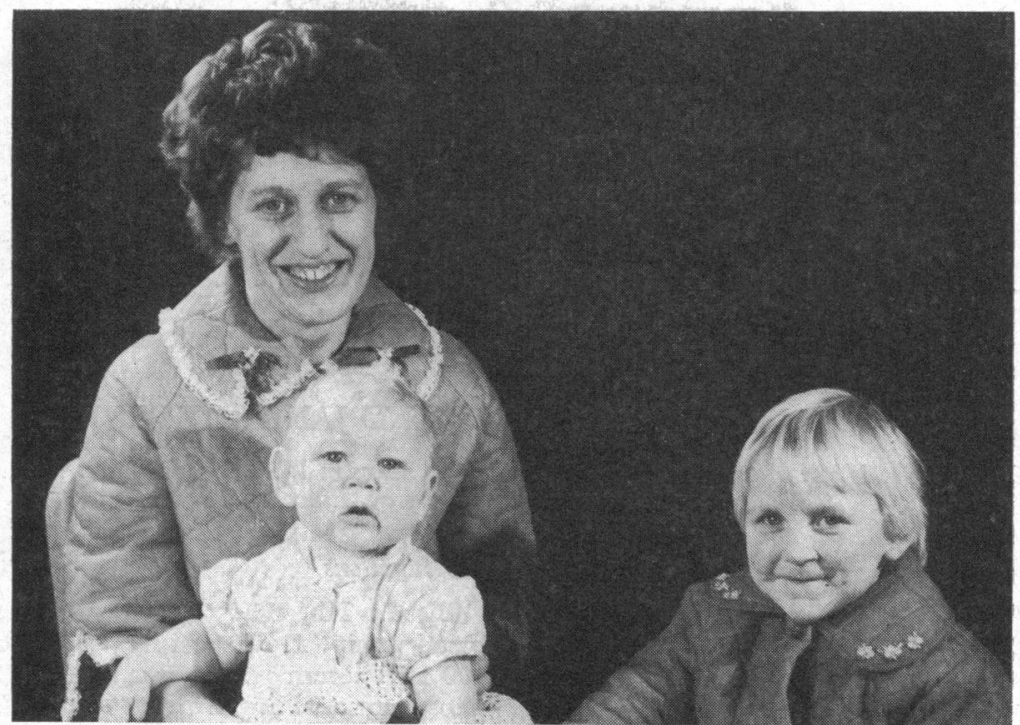

FIG. 1.-Mother, aged 25 (Case 1), and 2 affected children (Case 2 on right and Case 4), illustrating normal faces.

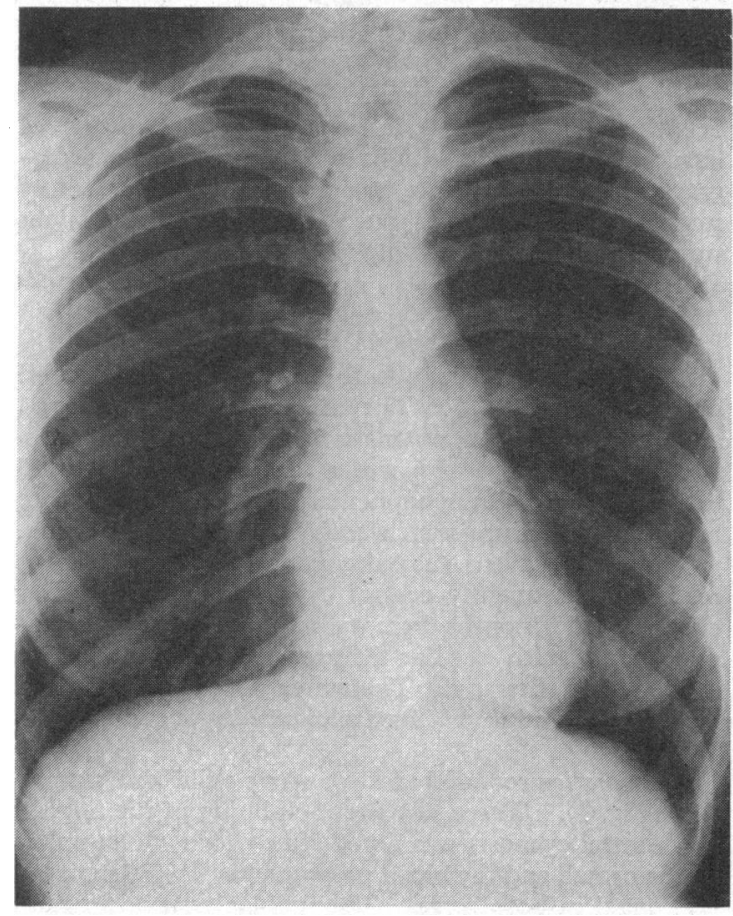

Fig. 2.-Chest radiograph of Case 1. Postero-anterior view showing normal-sized heart, with dilatation of the main pulmonary artery and oligaemic lung fields. closure with normal splitting of the second sound, and a late systolic murmur in the pulmonary area was well heard over both lungs.

\section{Investigations}

Blood. Hb, 11.7 g. $/ 100 \mathrm{ml}$; ESR, $14 \mathrm{~mm} . / \mathrm{hr}$; blood group, $A \mathrm{Rh}$ positive; serum calcium, $9.2 \mathrm{mg}$./ $100 \mathrm{ml}$; serum phosphorus, $3.8 \mathrm{mg} . / 100 \mathrm{ml}$; alkaline phosphatase, 25 King-Armstrong units; karyotype, normal female.

Urinary excretion of mucopolysaccharide and hydroxyproline normal. Chest radiograph showed cardiac enlargement with oligaemic lung fields (Fig. 4). Electrocardiogram showed right axis deviation with severe right ventricular hypertrophy. Cardiac catheterization (Table) confirmed the high main pulmonary artery pressure. The left atrium was reached through a patent foramen ovale, and oxygen saturations indicated a small right-to-left shunt at atrial level. The pulmonary venous blood was fully saturated.

The right ventricular angiocardiogram demonstrated enlargement and hypertrophy of the right ventricle; the pulmonary valve was normal. The main pulmonary artery was slightly dilated, but the right and left pulmonary arteries were of normal size. The first and second branches of the pulmonary arteries were of normal size. The first and second branches of the pulmonary arteries showed multiple stenoses, with associated post-stenotic dilatation (Fig. 5a). In the left-sided phase of the angiogram a supravalvar aortic stenosis was visible (Fig. 5 b). 


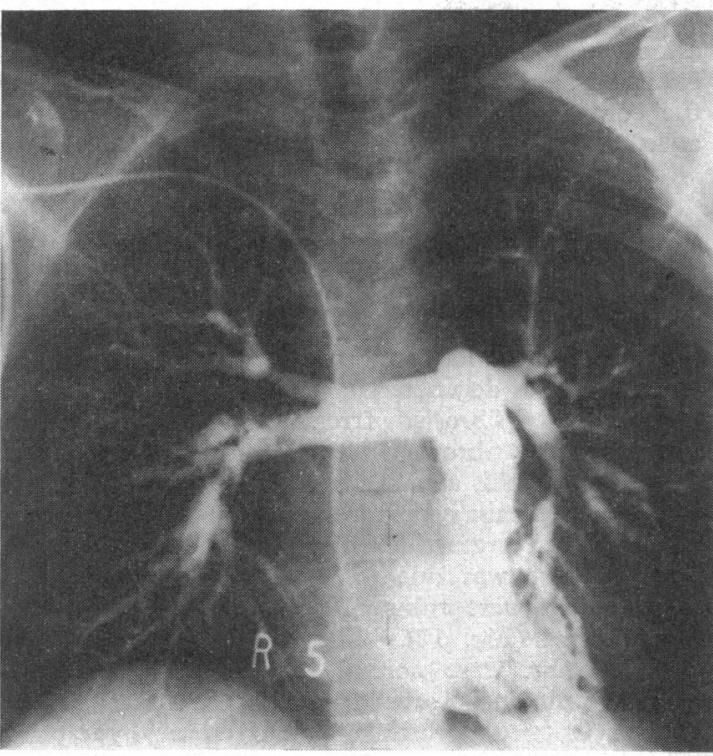

(a)

FIG. 3.-(a) Right ventricular angiogram, antero-posterior view, showing slight dilatation of main pulmonary artery and multiple peripheral pulmonary artery stenoses, with poststenotic dilatations. (b) Aortogram, lateral view, showing supravalvular aortic stenosis.

\section{Case 3}

A female child who died at 10 weeks. The infant developed symptoms of pyloric stenosis, and an operation to relieve this was carried out at the age of 6 weeks. Two days after discharge from hospital the infant was found dead.

Post-mortem findings (by L.M.G.). The body was that of a thin female infant $56 \mathrm{~cm}$. long, with a healed right epigastric operation scar. Apart from a deeply healed surgical incision in the anterior aspect of the thickened pylorus, there was no abnormality outside the cardiovascular system. The pleural and pericardial cavities were normal. The lungs showed acute con-

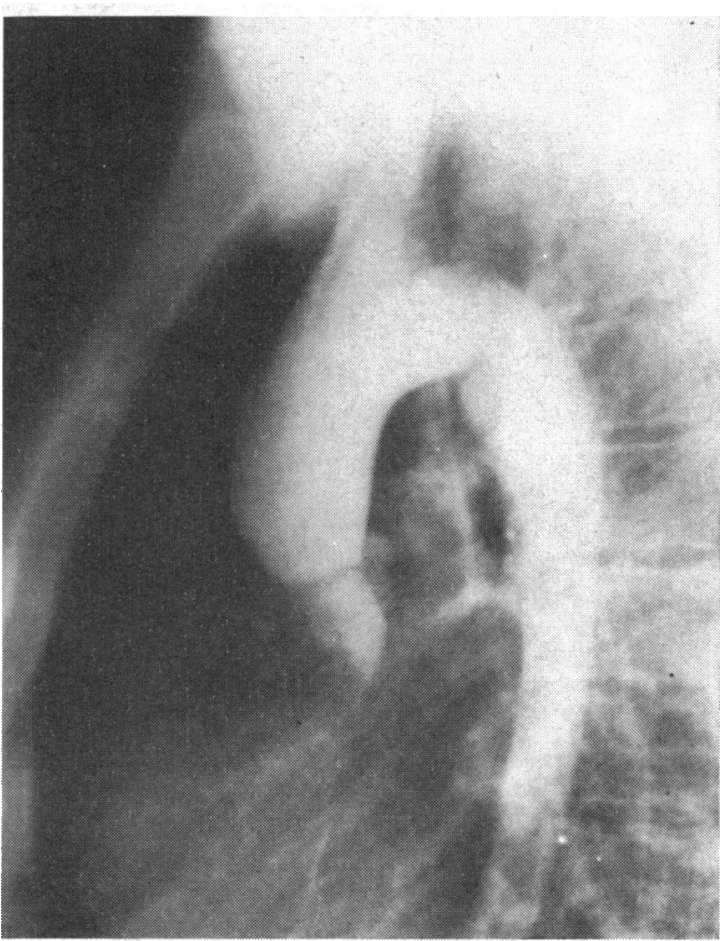

(b)

gestion and oedema evenly distributed throughout all zones, and there was a moderate amount of frothy fluid in the larger air passages.

The heart was normal in size and shape with normal systemic venous connexions. There was a probe patent foramen ovale and bulging of the septum secundum into the left atrium. The atrioventricular and semilunar valves were normal. The right ventricular myocardium was moderately thickened $(0.4 \mathrm{~cm}$.). The pulmonary trunk, the aorta, and their main branches showed a uniform increase in the thickness of the walls which were up to $0.2 \mathrm{~cm}$. thick (Fig. 6). The lumens were regular and the endothelial lining was smooth; the orifices of the main branches were considerably narrowed

TABLE

CATHETERIZATION DATA ON CASES 1, 2, AND 4

\begin{tabular}{|c|c|c|c|c|c|c|c|c|c|}
\hline \multirow[b]{2}{*}{ Patient } & \multicolumn{7}{|c|}{ Pressures (mm. Hg) } & \multicolumn{2}{|c|}{ Oxygen saturation $(\%)$} \\
\hline & $\begin{array}{l}\text { Right } \\
\text { atrium }\end{array}$ & $\underset{\text { ventricle }}{\text { Right }}$ & $\begin{array}{c}\text { Main } \\
\text { pulmonary } \\
\text { artery }\end{array}$ & $\begin{array}{c}\text { Distal } \\
\text { pulmonary } \\
\text { artery }\end{array}$ & $\begin{array}{c}\text { Left } \\
\text { atrium }\end{array}$ & $\begin{array}{c}\text { Left } \\
\text { ventricle }\end{array}$ & $\begin{array}{c}\text { Aorta } \\
\text { or artery }\end{array}$ & $\begin{array}{c}\text { Aorta } \\
\text { or artery }\end{array}$ & $\begin{array}{l}\text { Pulmonary } \\
\text { artery }\end{array}$ \\
\hline Case 1 & $\begin{array}{l}a=6 \\
v=6\end{array}$ & $55 / 0$ & $52 / 13$ & $35 / 10$ & $\begin{array}{l}a=10 \\
v=10\end{array}$ & $130 / 0$ & $130 / 75$ & 98 & 73 \\
\hline Case 2 & $\begin{array}{l}a=9 \\
v=6\end{array}$ & $140 / 0$ & $130 / 15$ & - & $\begin{array}{l}a=8 \\
v=7\end{array}$ & 一 & $90 / 50$ & 93 & 57 \\
\hline Case 4 & $a=12$ & $100 / 5$ & $100 / 12$ & - & $a=9$ & & - & 93 & 41 \\
\hline
\end{tabular}




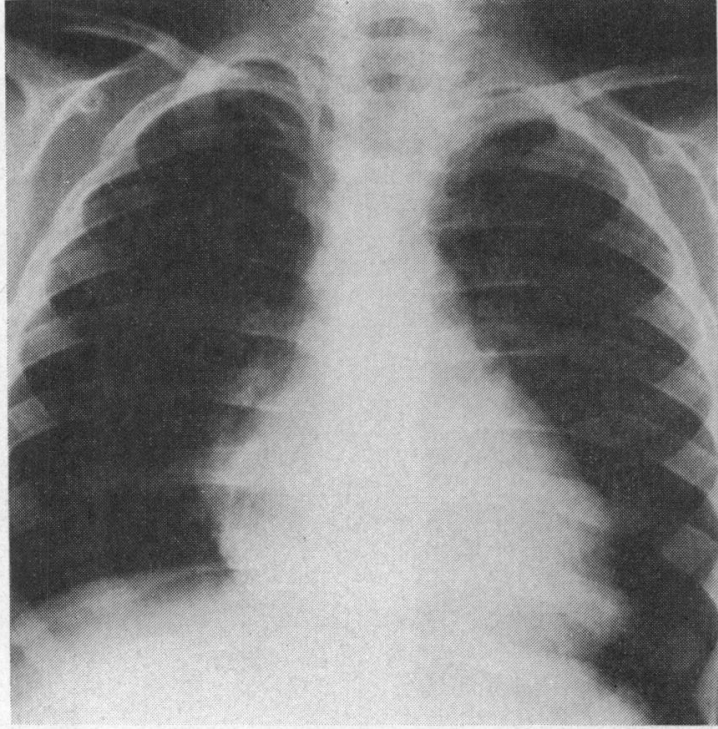

FIG. 4.-Chest radiograph of Case 2. Postero-anterior view showing moderate cardiac enlargement and oligaemic lung fields.

but were remarkably elastic and distensible on probing. This condition extended throughout the whole length of the aorta and its main branches, the appearance of the vessels resembling cooked macaroni (Fig. 7). The peripheral vessels were not dissected, but the changes were well marked in the common iliac, subclavian, and carotid arteries. The pulmonary artery trunk showed the most thickening; at the lung hila the pulmonary arteries were of normal calibre and only slightly thickened. The coronary artery orifices were narrowed, but the coronary vessels themselves were not apparently affected.

Histology. The incised pylorus showed marked hyperplasia of the circular muscle fibres. In the heart there was slight simple thickening of the endocardium of the left atrium without evidence of fibro-elastosis. The heart valves were normal. The inner trabeculated zone of the left ventricular myocardium showed patchy areas of degenerative changes in the muscle and some areas of fibrosis. Irregular foci of calcification surrounded by fibrous tissue measuring 0.1 to $1 \mathrm{~mm}$. were found in this area of myocardium (Fig. 8).

The aorta, main systemic arteries, and the pulmonary trunk showed gross thickening of the media (Fig. 9). This increase was due to hyperplasia of the elastic fibres which were thinner but much closer together than normal (Fig. 10). The intima, adventitia, and vasa vasorum were normal. The larger and intermediate pulmonary arteries within the lungs showed only slight medial thickening and elastic hyperplasia (Fig. 11) without apparent stenosis. The pulmonary arterioles were normal. The lung tissue showed slight bronchiolitis and early bronchopneumonia. No abnormal features were noted in the small arteries or arterioles of the various viscera.

\section{Case 4}

A girl aged 9 months. No murmur was noted at birth, but a murmur was heard at the age of 2 months. The child was active and without symptoms, and

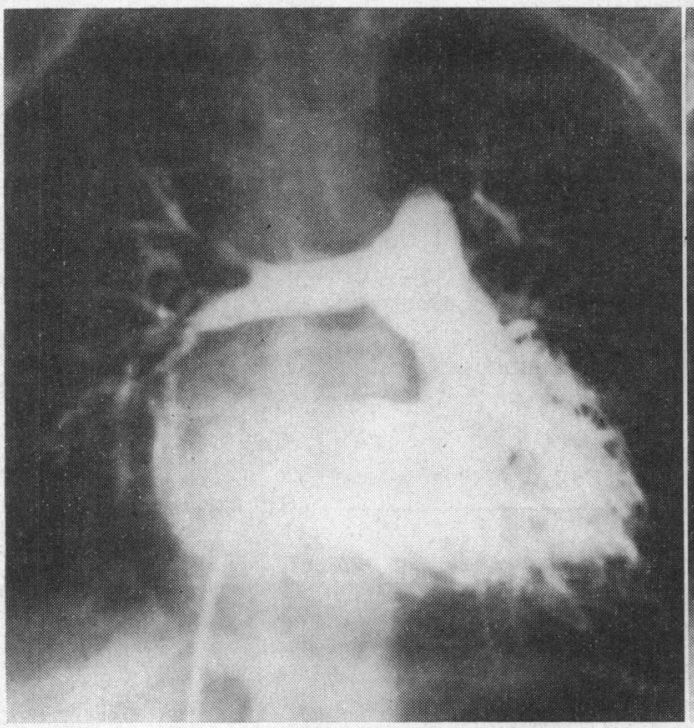

(a)

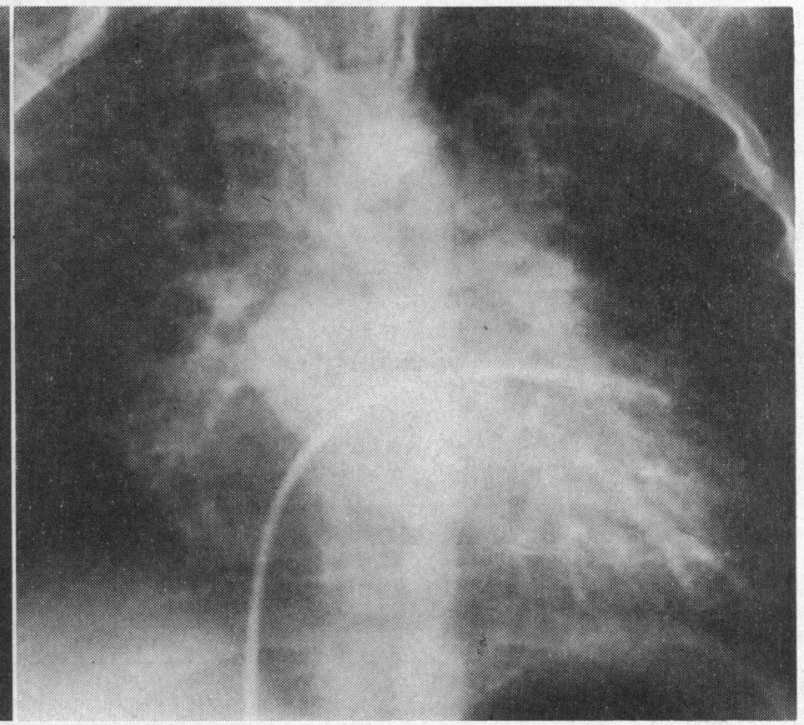

(b)

FIG. 5.-(a) Right ventricular angiogram, antero-posterior view, showing enlargement of the right ventricle. The first and second branches show multiple stenoses. (b) Left-sided phase of right ventricular injection, antero-posterior view, showing slight supravalvular aortic stenosis (retouched for clarity in reproduction). 


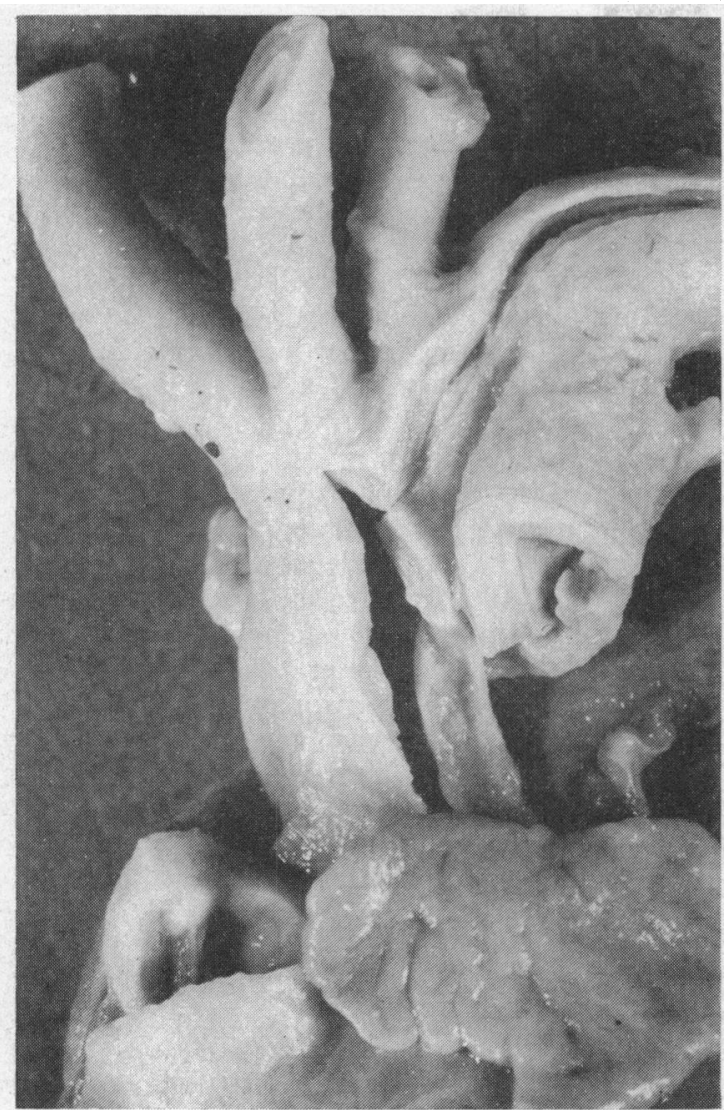

FIG. 6.-Post-mortem specimen, Case 3, showing abnormal thickness of the wall of the pulmonary trunk and the aorta.

examination showed her to be normally developed and alert (Fig. 1). No cyanosis at rest or on exertion was noted. The blood pressure was $90 / 60 \mathrm{~mm}$. $\mathrm{Hg}$ and all pulses were equal. The jugular venous pressure showed a dominant " $a$ " wave. The cardiac impulse was of right ventricular type. On auscultation the first sound was followed by a loud ejection systolic murmur loudest in the pulmonary area, and the pulmonary component of the second sound was increased. No other abnormality was detected.

\section{Investigations}

Blood. $\mathrm{Hb}, 10.6$ g. $/ 100 \mathrm{ml}$; ESR, $6 \mathrm{~mm} . / \mathrm{hr}$;; blood group, $\mathrm{O} \mathrm{Rh}$ positive; serum calcium, $10 \mathrm{mg}$./ $100 \mathrm{ml}$.; serum phosphorus, $4 \cdot 2 \mathrm{mg}$./100 ml.; karyotype, normal female.

Urinary excretion of mucopolysaccharides and hydroxyproline, normal. Chest radiograph showed some cardiac enlargement with oligaemic lung fields (Fig. 12). Electrocardiogram showed right axis deviation and severe right ventricular hypertrophy.

Cardiac catheterization (Table) revealed high pul-

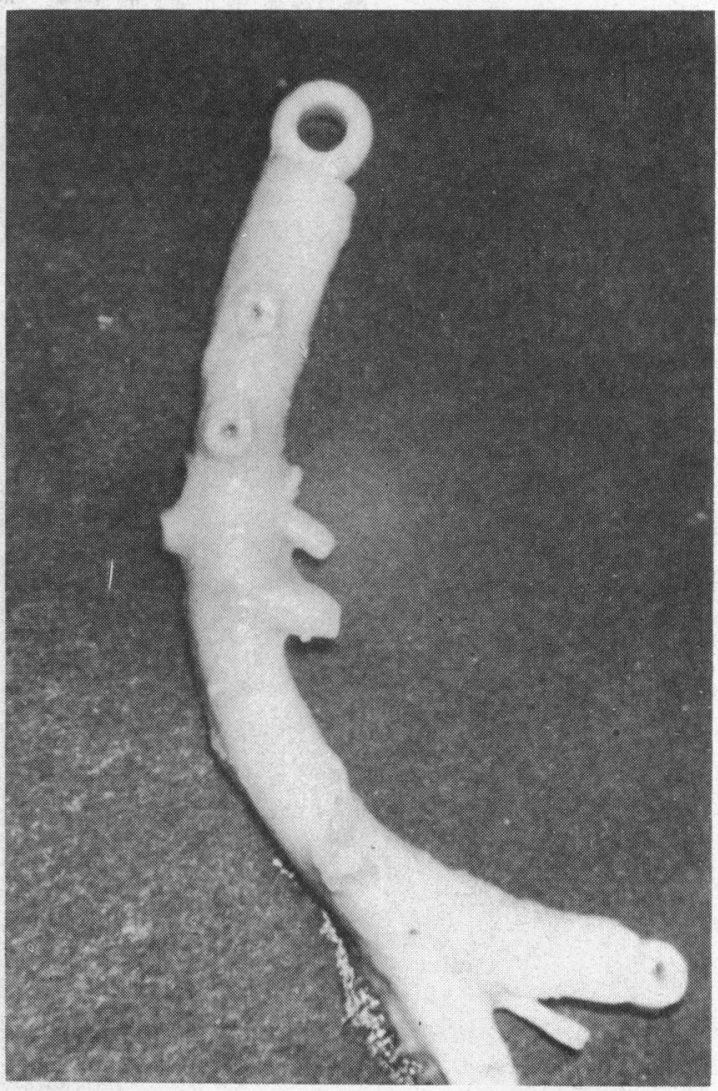

Fig. 7.-Post-mortem specimen, Case 3, showing the thickened walls and narrowed orifices of the main branches of the abdominal aorta.

monary artery and right ventricular pressures. A patent foramen ovale was demonstrated. The study was complicated by atrioventricular block and supraventricular tachycardia.

Right ventricular angiocardiography showed enlargement of the main pulmonary artery. There was diffuse severe stenosis (Fig. 13) of the right and left pulmonary arteries from their origin at the bifurcation of the main pulmonary artery. The distal pulmonary arteries were small. The left side of the heart and aorta were not clearly opacified owing to the slow circulation through the lungs.

\section{Family History}

The pedigree of this family is shown (Fig. 14). The only other child of Case 1 was a boy aged 6 years who had no signs of cardiovascular abnormality on examination, chest radiography, or electrocardiography. A maternal aunt of Case 1 died, age 21 years, of congenital heart disease, but the nature of the lesion is unknown. There was no other certain family history of congenital abnormality in four generations. 


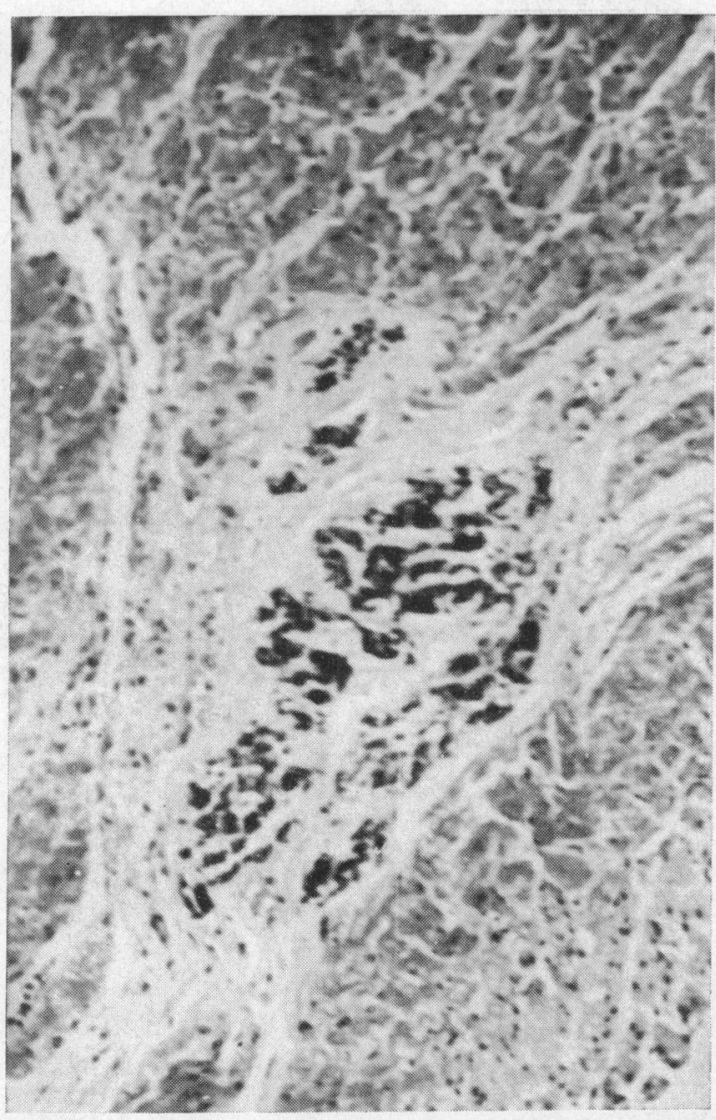

FIg. 8.-Left ventricular myocardium. Area of fibrous tissue surrounding focus of calcification. (H. and E. $\times 40$.)

\section{Discussion}

Multiple pulmonary artery stenoses may be associated with other congenital abnormalities of the heart (McCue et al., 1965) or occur as isolated lesions. In the present group of patients the stenoses appear to have resulted from a generalized arterial disease affecting large arteries. In the one patient aged 10 weeks who died, all major arteries were diffusely thickened, looking like "macaroni". Localized stenoses of the pulmonary arteries were not present, but there was a change in the pathology of the vessels where the pulmonary arteries entered the lung. It is possible that had the child survived, stenoses would have developed at the site of these transitional changes. It is possible that the disease was most severe in the child who died, and it was similar in the youngest living child in whom angiocardiography showed diffuse narrowing of the pulmonary arteries and no localized stenoses. It is assumed that the pathology of the vessels in each patient is the same but is less severe in the oldest survivor, namely the 25-year-old mother. An alternative explanation for the varying physiological and anatomical effects of this arteriopathy is that the haemodynamic consequences become less with age and growth.

The histology in Case 3 showed that the arterial thickening was due to diffuse hyperplasia of the elastic component in the large arteries of both the systemic and pulmonary circulations. The elastic fibres were thinner but closer together than normal. This differs from the histology following maternal rubella infection associated with pulmonary artery stenosis, where the marked intimal hyperplasia has been found to be due to fibroblastic thickening with fragmented elastic fibres (Gay et al., 1963; Campbell, 1965; Schmidt and Rambo, 1965). Kahler et al. (1966) studied a 3-year-old boy with familial supravalvar aortic stenosis and multiple pulmonary arterial stenoses, and found severe intimal fibrosis and hypertrophy of the media of the aorta and pulmonary artery. Despite the clinical similarity of Kahler's patient with the present series, the arterial pathology was quite different. In patients with infantile hypercalcaemia who may also have multiple arterial stenoses, the pathology of the vessels is different from this arteriopathy. Schlesinger, Butler, and Black (1956) found fragmentation of the elastica with medial hypertrophy, and in a further study of hypercalcaemics Black and Bonham Carter (1963) and Black, Butler, and Schlesinger (1965) described fibroses of the aortic media with deficient muscular and elastic layers. Elastic tissue proliferation in the media has been described in association with pulmonary artery stenoses (Orell, Karnell, and Wahlgren, 1960; MacMahon, Ho Yong Lee, and Stone, 1967), but no one has referred to such a diffuse arteriopathy looking like macaroni. None of the clinical features of a mucopolysaccharidosis or of Marfan's syndrome were present, and the urinary excretion of mucopolysaccharides and hydroxyproline were normal, thus excluding the possibility of mucopolysaccharidosis. The myocardial foci of calcification seen in Case 3 were possibly due to ischaemia secondary to narrowing in coronary orifices rather than to dystrophic deposition. The areas of surrounding fibrosis suggest that there may have been some patchy necrosis previously.

Familial occurrence of pulmonary artery stenoses has been infrequently reported. It has been noted in a mother and son (Gyllenswärd et al., 1957) and observed in two brothers (Van Epps, 1957; McCue et al., 1965) and three sibs (Arvidsson et al., 1961). Different members of the same family may have pulmonary artery and supra-aortic stenosis separ- 


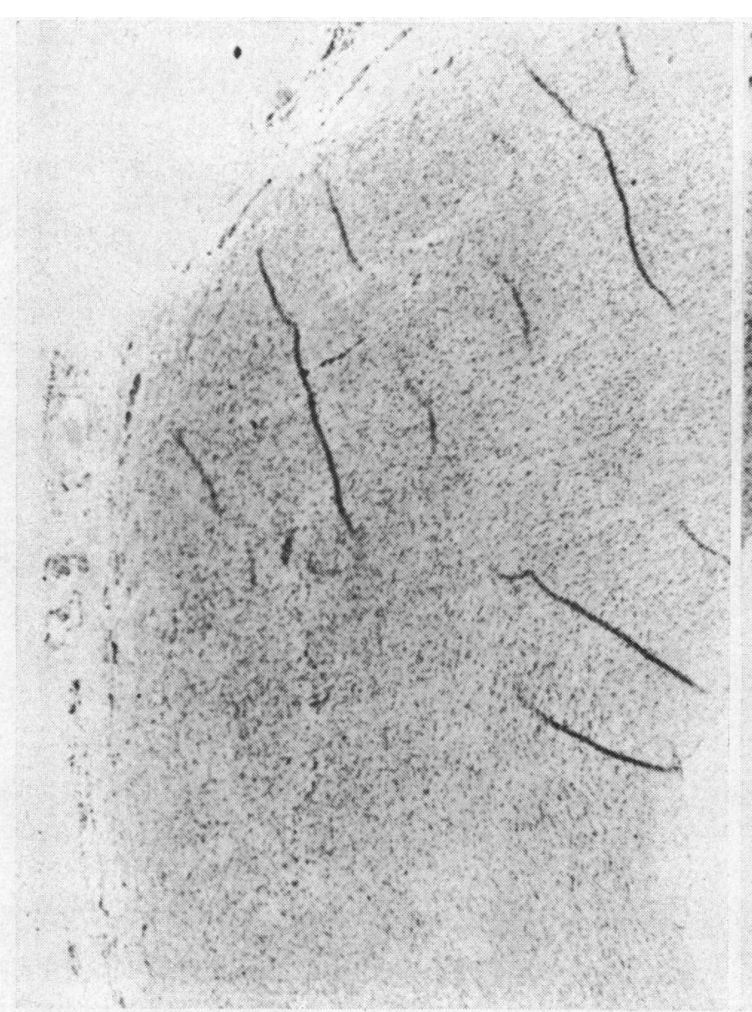

(a)

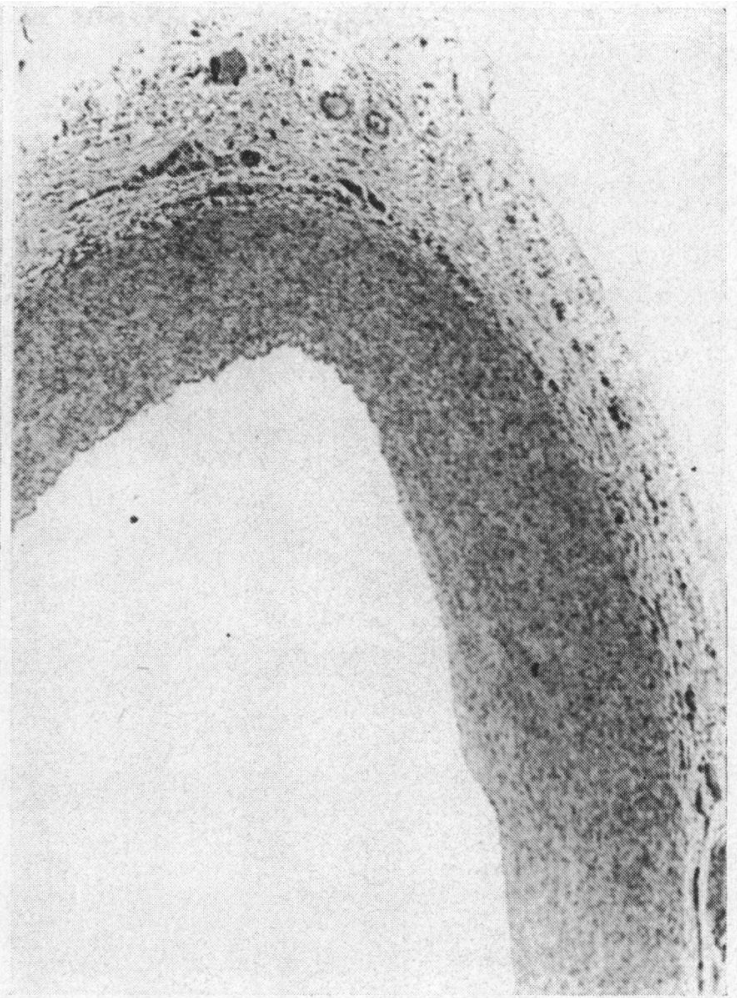

(b)

Fig. 9.-(a) Pulmonary trunk. Histology showing increase in elastic tissue and gross thickening of the media. (b) Normal infantile pulmonary trunk for comparison. (H. and E. $\times 40$.)

ately or in combination, with varying severity (Merritt et al., 1963; Eisenberg et al., 1964; Kahler et al., 1966). On the basis of pedigree analysis (Merritt and his colleagues, 1963), it has been concluded that the abnormality may be transmitted as an autosomal dominant with variable expression, which is consistent with the present findings. Karyotypes were normal in our patients as in all except one of Merritt's patients who had a 46/47 mosaic. Histological data in these familial cases are scanty, so it is unknown if the arteriopathy was the same as in this report.

A generalized arterial abnormality is clearly the cause of these stenoses. Arterial narrowing may be diffuse, and of varying severity, in this syndrome of "macaroni arteriopathy", as in hypercalcaemic patients, but the histology is different. However, the mental normality, with normal dentition and facies distinguishes the two groups of patients. It is possible that an intrauterine metabolic defect gives rise to the "macaroni arteriopathy", as has been suggested in idiopathic hypercalcaemia of infancy (Black and Bonham Carter, 1963; Garcia et al., 1964; Jue, Noren, and Anderson, 1965). However, no evidence about aetiology is available.

Though a definite bedside diagnosis of pulmonary artery stenoses may be difficult in the infant, several features may suggest that the obstruction is not in the pulmonary valve. The long systolic murmur increasing on inspiration and associated with right ventricular hypertrophy may be atypically placed and heard well over the lung fields. Occasionally a continuous murmur over the lung fields may be present; this murmur, as in Case 1, has been attributed to flow in dilated bronchial vessels (Lees and Dotter, 1965), but these were not marked in this patient, and it is more likely to have arisen from the site of obstruction. It is important to distinguish the condition from pulmonary valve stenosis. The absence of an ejection click in patients presenting with pulmonary ejection systolic murmurs indicates that the site of obstruction is probably not valvular, and the increased intensity of the pulmonary component of the second sound denies the presence of valvar or subvalvar pulmonary stenosis. These findings 


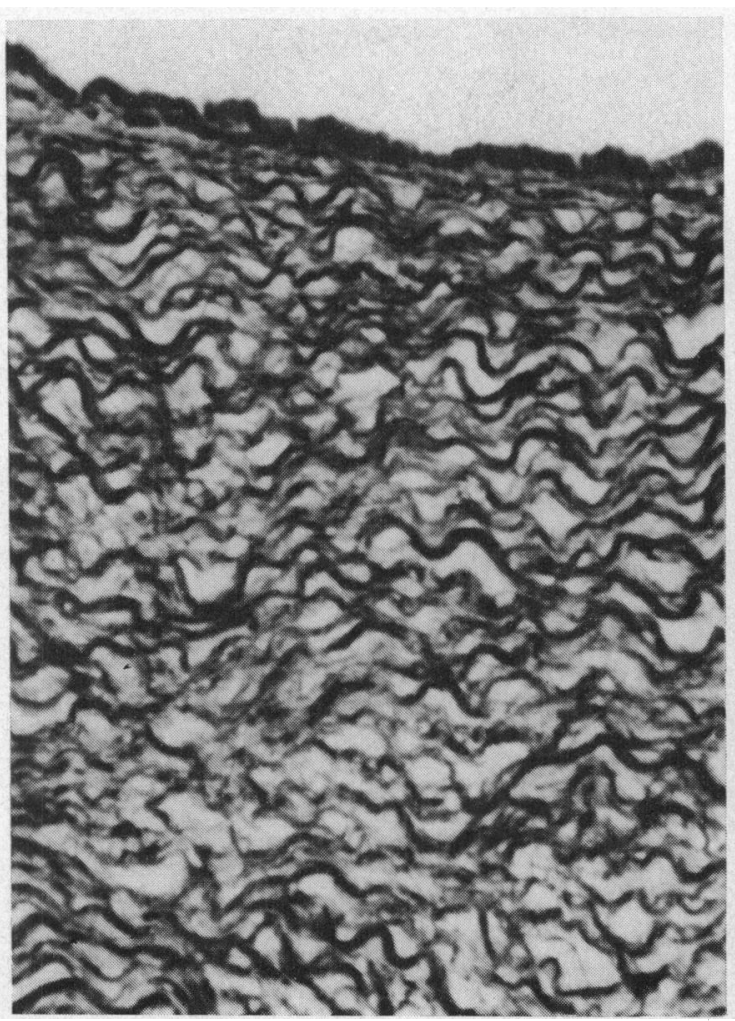

(a)

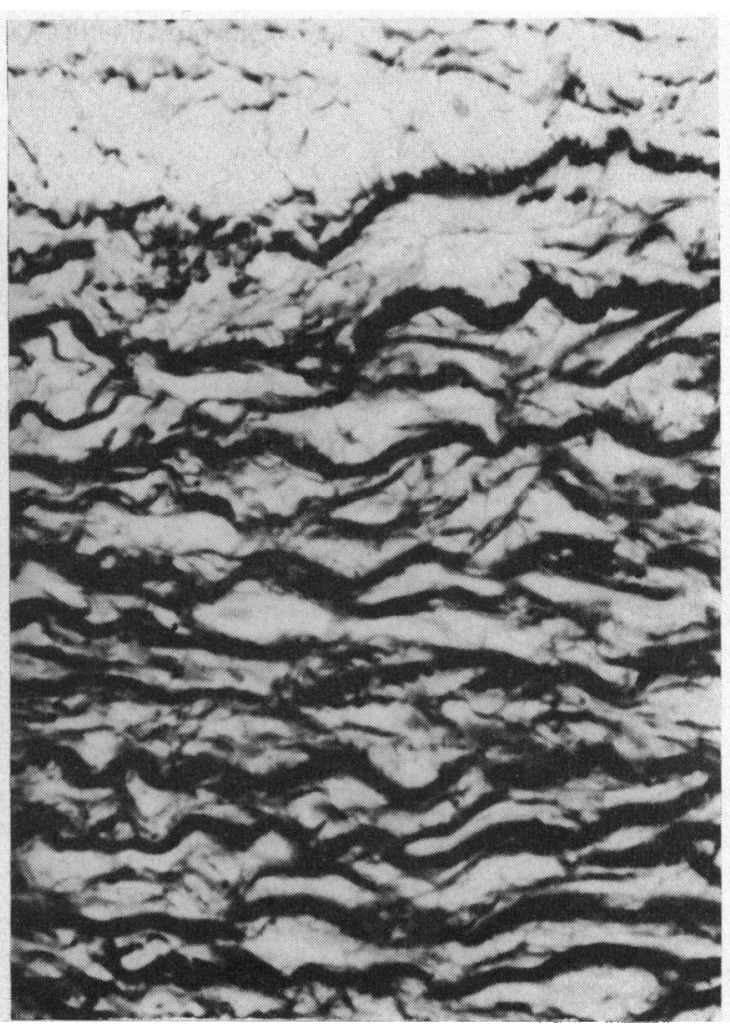

(b)

FIG. 10.-(a) Aorta. Notice increase in elastic fibres. (b) Normal infantile aorta for comparison. (Orcein elastic stain. $\times 480$.)

suggest primary pulmonary hypertension (Van Epps, 1957), but the length of the systolic murmur makes this unlikely, and further investigation is always necessary to demonstrate the origin of these signs.

Right heart catheterization with measurement of pulmonary artery pressures may be diagnostic if the stenotic area can be crossed. This was not possible in the two youngest patients, and proof of the cause of the pulmonary hypertension depended on the angiocardiogram. The characteristic pulmonary artery wide pulse pressure and low diastolic pressure were present in our patients (Agustsson et al., 1962). It is important to diagnose the cause of the pulmonary hypertension, as the prognosis appears to differ from primary pulmonary hypertension. The natural history of this arteriopathy is unknown, but in severe cases of pulmonary involvement it may lead to right heart failure in early life. The possibility of regression with growth taking place is suggested by the apparent inverse severity with age.
A diffuse arterial disease causing multiple pulmonary artery stenoses was found in a mother and three female children. Two patients also had supra-aortic stenosis demonstrated by angiography. The macroscopical appearance of the arteries in the youngest child resembled "macaroni". The histological findings in the youngest child indicated that the principal abnormality was hyperplasia of the elastic tissue in the media of the larger arteries of both the systemic and pulmonary circulation. There was an apparent inverse relation between severity of obstruction and age.

We thank Dr. J. Hunter who referred the children, and Dr. M. Steel who looked after the mother, for permission to publish these cases.

We are grateful to Dr. R. Meredith, Department of Biology, the Middlesex Hospital, for the karyotypes, to Dr. Helen Muir, Kennedy Institute of Rheumatology, for estimation of urinary mucopolysaccharides, and to Dr. R. Smith, Department of Medicine, University College Hospital, for estimation of urinary hydroxyproline. 


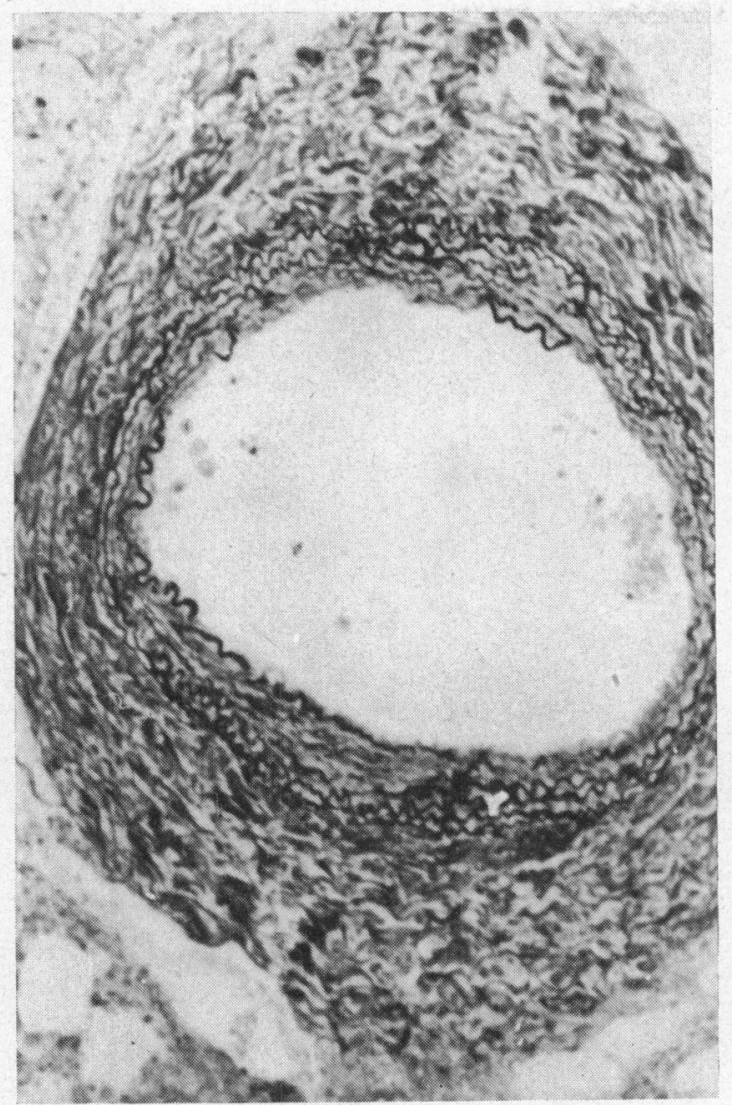

FIG. 11.-An intermediate-sized pulmonary artery showing slight medial thickening and elastic hyperplasia. (Orcein elastic. $\times 120$.)

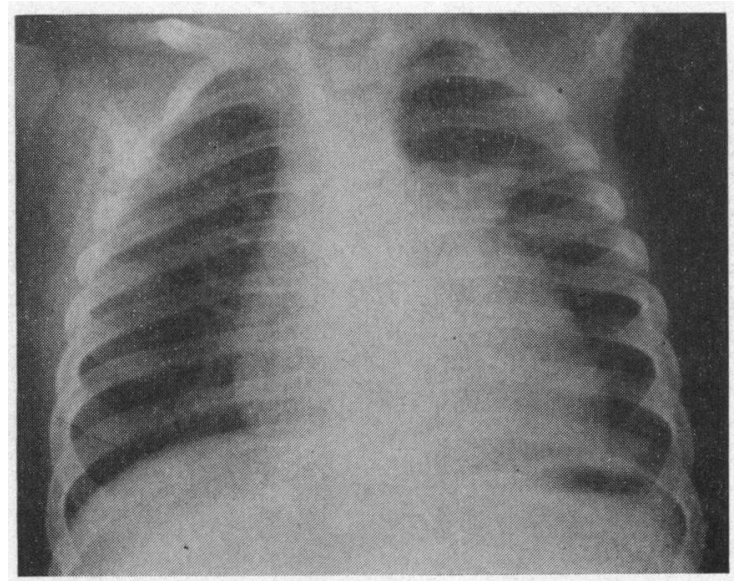

FIG. 12.-Chest radiograph of Case 4. Postero-anterior view showing cardiac enlargement and oligaemic lung fields.

\section{REFERENCES}

Agustsson, M. H., Arcilla, R. A., Gasul, B. M., Bicoff, J. P., Nassif, S. I., and Lendrum, B. L. (1962). The diagnosis of bilateral stenosis of the primary pulmonary artery branches based on characteristic pulmonary trunk pressure curves. Circulation, 26, 421 .

Arvidsson, H., Carlsson, E., Hartmann, A., Tsifutis, A., and Crawford, C. (1961). Supravalvular stenoses of the pulmonary arteries. Acta. radiol. (Stockh.), 56, 466.

—, Karnell, J., and Möller, T. (1955). Multiple stenosis of the pulmonary arteries associated with pulmonary hypertension, diagnosed by selective angiocardiography. Acta. radiol. (Stockh.), 44, 209.

Beuren, A. J., Schulze, C., Eberle, P., Harmjanz, D., and Apitz, J. (1964). The syndrome of supravalvular aortic stenosis, peripheral pulmonary stenosis, mental retardation and similar facial appearance. Amer. F. Cardiol., 13, 471 .

Black, J. A., and Bonham Carter, R. E. (1963). Association between aortic stenosis and facies of severe infantile hypercalcaemia. Lancet, 2, 745.

-, Butler, N. R., and Schlesinger, B. E. (1965). Aortic stenosis and hypercalcaemia. Lancet, $2,546$.

Bourassa, M. G., and Campeau, L. (1963). Combined supravalvular aortic and pulmonic stenosis. Circulation, 28, 572.

Campbell, P. E. (1965). Vascular abnormalities following maternal rubella. Brit. Heart f., 27, 134.

Chevers, N. (1846). A collection of facts illustrative of the morbid conditions of the pulmonary artery. Lond. med. Gaz., 38, 189, 276, 369, 452, 699, 744, 828, 961, and 1087.

Eisenberg, R., Young, D., Jacobson, B., and Boito, A. (1964). Familial supravalvular aortic stenosis. Amer. F. Dis. Child., 108, 341.

Emmanouilides, G. C., Linde, L. M., and Crittenden, I. H. (1964). Pulmonary artery stenosis associated with ductus arteriosus following maternal rubella. Circulation, 29, 514.

Garcia, R. E., Friedman, W. F., Kaback, M. M., and Rowe, R. D. (1964). Idiopathic hypercalcemia and supravalvular aortic stenosis. Documentation of a new syndrome. New Engl. F. Med., 271, 117.

Gay, B. B., Franch, R. H., Shuford, W. H., and Rogers, J. V. (1963). The roentgenologic features of single and multiple coarctations of the pulmonary artery and branches. Amer. F. Roentgenol., 90, 599.

Gyllenswärd, A., Lodin, H., Lundberg, A., and Möller, T. (1957). Congenital, multiple peripheral stenoses of the pulmonary artery. Pediatrics., 19, 399.

Jue, K. L., Noren, G. R., and Anderson, R. C. (1 965) The syndrome of idiopathic hypercalcemia of infancy with associated congenital heart disease. F. Pediat., 67, 1130.

Kahler, R. L., Braunwald, E., Plauth, W. H., and Morrow, A. G. (1966). Familial congenital heart disease. Amer. F. Med., 40, 384.

Lees, M. H., and Dotter, C. T. (1965). Bronchial circulation in severe multiple peripheral pulmonary artery stenosis. Circulation, 31, 759.

McCue, C. M., Robertson, L. W., Lester, R. G., and Mauck, H. P. (1965). Pulmonary artery coarctations. f. Pediat., 67, 222.

MacMahon, H. E., Ho Yong Lee, and Stone, P. A. (1967). Congenital segmental coarctation of the pulmonary artery (an anatomic study). Amer. F. Path., 50, 15.

Merritt, A. D., Palmer, C. G., Lurie, P. R., and Petry, E. L. (1963). Supravalvular aortic stenosis: genetic and clinical studies. (Abstract.) F. Lab. clin. Med., 62, 995. 


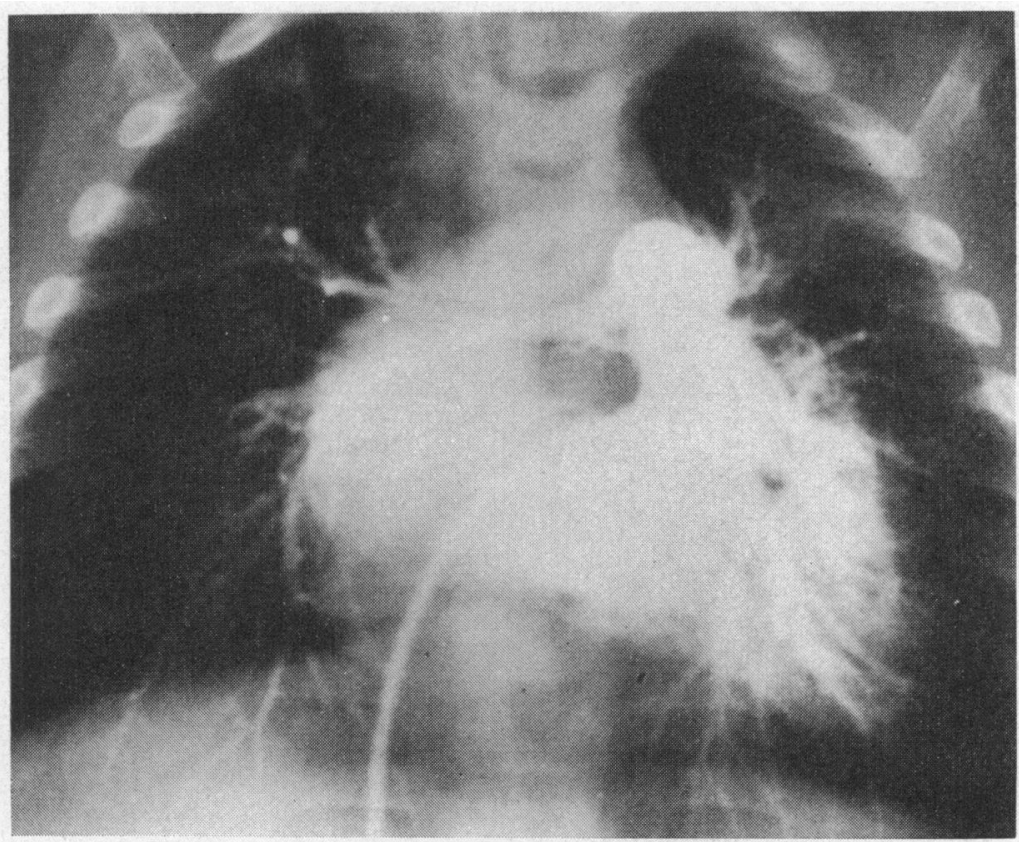

FIG. 13.-Right ventricular angiogram, antero-posterior view, showing severe diffuse stenosis of the right and left pulmonary arteries from close to their origin. The distal arteries are extremely small.

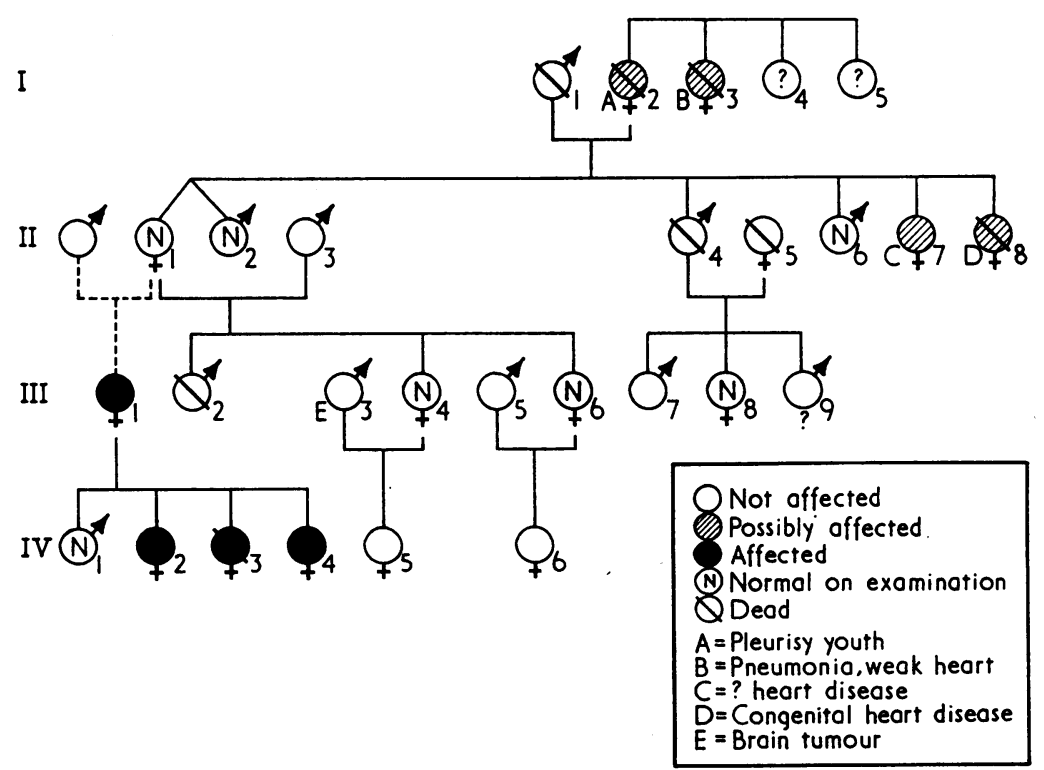

FIG. 14.-Family pedigree showing affected members. 
Mudd, J. G., Walter, K. E., and Willman, V. L. (1965). Pulmonary artery stenosis: diagnostic and therapeutic considerations. Amer. F. med. Sci., 249, 125.

Orell, S. R., Karnell, J., and Wahlgren, F. (1960). Malformation and multiple stenoses of the pulmonary arteries with pulmonary hypertension. Acta. radiol. Stockh.), 54, 449.

Rowe, R. D. (1963). Maternal rubella and pulmonary artery stenoses. Pediatrics, 32, 180.

Schlesinger, B. E., Butler, N. R., and Black, J. A. (1956). Severe type of infantile hypercalcaemia. Brit. med. $\mathcal{F}$., $1,127$.

Schmidt, D. M., and Rambo, O. M. (1965). Segmental intimal hyperplasia of the abdominal aorta and renal arteries producing hypertension in an infant. Amer. f. clin. Path., 44, 546.

Schwalbe, E. (1909). Die Morphologie der Missbildungen, Part 3, p. 426. Gustav Fischer, Jena.

Van Epps, E. F. (1957). Primary pulmonary hypertension in brothers. Amer. F. Roentgenol., 78, 471.

Watson, G. H. (1963). Supravalvar pulmonary and aortic stenosis coexisting. Brit. Heart $\mathcal{f}$., 25, 817.

William, J. C. P., Barratt-Boyes, B. G., and Lowe, J. B. (1961). Supravalvular aortic stenosis. Circulation, 24, 1311.

\section{ADDENDUM}

One of us (L.M.G.) has found this arteriopathy with diffuse elastic hyperplasia and arteries looking like macaroni in one other patient. The patient was a 39-year-old mentally defective woman who died in a mental institution after 3 days of vomiting. She had been said to be fit, though at 26 years a gallop rhythm was commented upon in the mitral area. The blood pressure was $155 / 110 \mathrm{~mm}$. Hg.

At necropsy the face and body appeared normal. The heart weighed $500 \mathrm{~g}$., and showed right atrial and right ventricular hypertrophy. The main pulmonary trunk was aneurysmal, and the arteries in the left lung were large and atheromatous. There was narrowing of the right pulmonary artery with thickening of the wall. The aorta and branches showed generalized narrowing and the wall was diffusely thickened. The histology of the aorta, main pulmonary artery, and proximal right pulmonary artery showed elastic hyperplasia as in Case 3. 